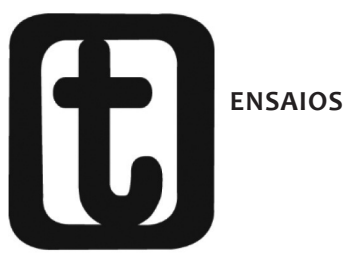




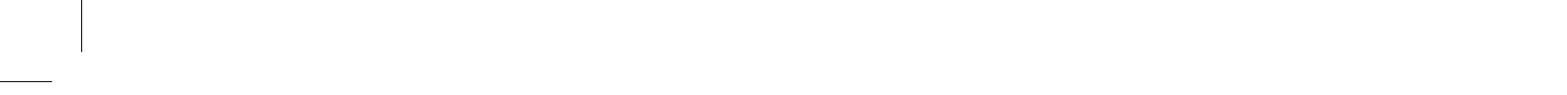




\title{
(t)
}

\section{O PROJETO DE FORMAÇÃO EM SERVIÇO SOCIAL: ANÁLISE DA SUA TRAJETÓRIA HISTÓRICA NO PERÍODO 1996 A 2016}

\author{
THE PROJECT OF TRAINING IN SOCIAL SERVICE: ANALYSIS OF ITS \\ HISTORICAL TRAJECTORY IN THE PERIOD 1996 TO 2016
}

\section{Alzira Maria Baptista Lewgoy' Ana Lúcia Suárez Maciel² $^{2}$}

\section{RESUMO}

$\mathrm{O}$ artigo se alicerça no resgate dos principais fatos conjunturais e profissionais que incidiram e alicerçaram o percurso empreendido pela formação em Serviço Social, abrangendo o período de 1996 a 2016. Para tanto, parte-se das análises documentais e bibliográficas que vêm sendo feitas por dois grupos de pesquisa cujo objeto de estudo é a formação na área. Objetiva-se contribuir com a reflexão, análise e crítica desse percurso, a partir de um balanço crítico dos principais aspectos que incidiram no mesmo, bem como sinalizar as polêmicas, os desafios e as estratégias de resistência, empreendidos pela categoria profissional, no horizonte de luta pela afirmação da direção crítica comprometida com a qualidade e direção social desse projeto de formação.

Palavras-chave: Formação. Projeto Profissional. Diretrizes Curriculares. Serviço Social.

\section{ABSTRACT}

The article is grounded in the rescue of the main cyclical and professional events that focused and underpinned the route undertaken by training in So-

\footnotetext{
1 Assistente Social, Professora e Pesquisadora do Curso de Serviço Social da Universidade Federal do Rio Grande do Sul - UFRGS.

2 Assistente Social, Professora e Pesquisadora do Curso de Serviço Social da Pontifícia Universidade Católica do Rio Grande do Sul- PUCRS.
} 


\section{temporollis}

cial Work, covering the period from 1996 to 2016. Therefore, it is part of the documentary analyzes that have been made by two groups research whose object of study is the training in the area. It aims to contribute to the discussion and critical analysis of this journey, from a critical review of the main aspects focused on it, as well as signal the controversies, challenges and strategies of resistance, made by category, on the horizon fighting the affirmation of critical direction committed to quality and social direction of this training project.

Keywords: Formation. Professional Project. Curriculum Guidelines. Social Work.

Submissão - 12/09/2016 Aceite - 13/01/2017

\section{Introdução}

O ano de 1996 marcou um fato histórico fundamental para a formação em Serviço Social no Brasil, pois resultou na aprovação das diretrizes gerais para o Curso de Serviço Social, cujo processo foi fruto de debate e construção coletiva da categoria profissional, bem como do amadurecimento acadêmico e organizativo da profissão. Coincidiu, também, com a aprovação da Lei de Diretrizes e Bases da Educação (LDB), neste mesmo ano, o que determinou a conformação que tal projeto viria a ter no seu processo de implantação e, posteriormente, enraizamento nas Unidades de Formação Acadêmicas (UFAs), pois é sabido que as mudanças que se processaram na política de educação superior foram responsáveis por um conjunto de inflexões no âmbito da formação de todos os profissionais.

A entrada no século XXI, no que se refere ao contexto da política de educação superior (brasileira e mundial) e os seus rebatimentos na formação em Serviço Social demarcaram um cenário de risco para o recente projeto de formação na área, posto que alteraram um conjunto de elementos que configuram o ensino superior. No seu conjunto, expressam contradições e mediações que se traduzem na disputa pela direção a ser dada à política de educação superior e, nela, a concepção de educação como direito social. Fortes regressões na direção contrária a esta concepção vêm sendo feitas pelo Estado e o mercado, expressas pela presença massiva do setor privado na oferta deste nível de ensino e pela mercantilização desse direito, conformando, assim, a contrarreforma da educação. 


\section{tempordils}

Medidas de austeridade são aplicadas nos países do capitalismo central e periférico, ameaçando os avanços nos âmbitos dos direitos e do Estado Social, trazendo implicações, tanto para os países europeus quanto latino-americanos, tais como: aumento expressivo de desemprego, precarização do trabalho, redução salarial, privatizações, inclusive da educação superior, transformando-a em mercadoria, cujas características estão na sua condição de ser produzida de maneira rápida e a baixo custo. A Declaração de Bolonha (1999) construiu o caminho e a definição de qual educação e qual formação eram necessárias para o mercado comum europeu e, inclusive, internacional, rebatendo na política de educação no Brasil com fortes implicações na formação acadêmica e na investigação em Serviço Social nestas últimas décadas. Tais elementos causam-nos inquietações e a necessidade de reflexões, no solo da formação e do exercício profissional, para problematizá-lo, pois o mesmo vem nos desafiando, dia a dia na condição de acadêmicos, docentes, pesquisadores e profissionais de Serviço Social, ou seja, como trabalhadores que se vêem diante do desmonte dos seus direitos.

Diante deste cenário que envolve forças sociais extremamente destrutivas, identificamos, de forma dialética, ações de resistência que se expressam na defesa da formação profissional e na análise dos seus impactos sobre o exercício da profissão, senso, sem dúvidas, uma das principais frentes na luta da categoria profissional nesse período histórico, tendo em vista a necessidade de apreender esse cenário para definir a direção e a construção de estratégias capazes de garantir a qualidade da sua formação e a direção crítica do seu Projeto Profissional. É nesta perspectiva que, neste artigo, indagamos: como se constituiu o processo de efetivação do projeto de formação profissional no período histórico de 1996 a 2016? Esta é uma questão fundamental para empreender a análise da trajetória histórica que este artigo se propõe a fazer, tendo em vista a posição de defesa intransigente da direção adotada para a profissão e considerando que, apesar do quadro adverso da política de educação superior, é preciso levar em conta os processos e movimentos que a categoria empreendeu (e segue empreendendo) nestes vinte anos de construção do projeto de formação na área que completamos em 2016.

As fontes que alicerçam este artigo se sustentam nas pesquisas documentais e bibliográficas (GIL, 2010), com produções relacionadas ao objeto "formação em Serviço Social", que vimos fazendo no interior de dois grupos de pesquisa vinculados à área de concentra- 


\section{temporollis}

ção e estudo sobre os fundamentos, a formação e o trabalho profissional em Serviço Social, com base em documentos legais da política nacional e internacional de educação superior, e da profissão no âmbito da Associação Brasileira de Ensino e Pesquisa em Serviço Social (ABEPSS), e do Conselho Federal de Serviço Social (CFESS), tais como Resoluções, Pareceres, Políticas, Plano de Lutas, Campanhas, entre outros e da produção de conhecimento da área, a saber: periódicos, livros e Anais dos Congressos Brasileiros de Assistentes Sociais (CBAS) e os Encontros de Estudos e Pesquisas em Serviço Social (ENPESS), Todas estas fontes compõem um acervo documental e bibliográfico dos referidos grupos, aqui utilizado de forma mista (CRESWELL, 2010), como aporte teórico do artigo.

No que se refere à estrutura, o artigo apresenta a lógica, a perspectiva de análise, o objetivo e as fontes que o alicerçam nesta introdução. Na seção seguinte, expõe sobre a trajetória histórica da formação em Serviço Social, discorrendo analiticamente sobre o período pós-Diretrizes Curriculares, de 1996 a 2016, a partir do resgate das configurações da formação na contemporaneidade, suas polêmicas, desafios e estratégias de resistência. $E$, por fim, busca dar visibilidade ao legado construído e aos futuros desafios que conformam o Projeto Profissional de Serviço Social neste âmbito, materializando o resgate histórico a que se propõe.

\section{A política de educação superior e a trajetória histórica da formação em serviço social nos últimos 20 anos}

O ano de 1996 foi significativo para o Serviço Social, pois culminou com a aprovação das Diretrizes Curriculares para o ensino na área e coincidiu, também, com a aprovação da Lei de Diretrizes e Bases da Educação (LDB) durante a vigência do governo de Fernando Henrique Cardoso. Tendo em vista esta legislação, uma importante ruptura foi implementada no planejamento do ensino superior, sendo necessário destacar as principais, a saber: a autonomia universitária, o fim dos currículos mínimos ${ }^{3}$ e a inclusão de uma nova modalidade de ensino superior (a distância). Devido a essas alterações, houve um atraso na

3 Esta legislação suprimiu os currículos mínimos que vigoravam no ensino superior e garantiam que as grades curriculares dos cursos fossem semelhantes em até $70 \%$ em todo o território nacional. Com a assunção das Diretrizes Curriculares, esse percentual e também os currículos mínimos foram suprimidos, gerando uma multiplicidade de desenhos de grades curriculares, que devem, no entanto, seguir as diretrizes curriculares definidas pelo Ministério da Educação. 


\section{tempordilis}

implementação das Diretrizes da área, já que o órgão regulador somente as aprovou no ano de 2002, em face das exigências da nova legislação nacional, bem como das disputas que se deram no âmbito de todas as categorias profissionais. É importante referir que, nesse período, a profissão se alicerçava no esforço de consolidação do Projeto Profissional, construído na década de 1980 e materializado na Lei de Regulamentação da Profissão (1993), no Código de Ética Profissional (1993) e nas Diretrizes Curriculares (DCs) (1996).

A reflexão proposta por Boschetti (2004) sobre as DCs, diante do cenário brasileiro da Educação Superior, também se relaciona à desconfiguração dela pelo Conselho Nacional de Educação no momento de sua aprovação, em 2002. Segundo a autora, não é possível refletir sobre as diretrizes curriculares e sua implementação sem considerar a situação e as tendências do ensino superior no Brasil, visto que as condições nas quais a educação superior se materializa, hoje têm um papel determinante no tipo de currículo implementado nas instituições de ensino superior e que têm impacto importante na implementação dos currículos em geral e do Serviço Social em particular.

Além disso, a entrada do século XXI sinalizava a existência de 79 cursos (BOSCHETTI, 2004), o que, no período atual, vai indicar uma nova conformação expressa pelos rebatimentos do que passaremos a explanar a seguir.

Em 2003, durante o primeiro governo de Luís Inácio Lula da Silva, foi apresentado o projeto de reforma universitária, que provocou as discussões iniciais acerca das reformas que viriam a ser processadas, independentemente da aprovação de tal projeto, mediante outras regulações, as quais, por fim, culminaram com o que alguns autores denominam de uma "reforma aos pedaços" (APUFSC, 2005). Essas reformas vêm rebatendo de forma incisiva na ampliação dos cursos de Serviço Social, na expansão desenfreada do ensino a distância e no crescimento do contingente profissional. Nesse mesmo período, a área participou da $1^{\mathrm{a}}$ edição do Exame Nacional de Desempenho de Estudantes (ENADE), que se constitui hoje em parte da política de avaliação adotada pelo MEC para os cursos de graduação. É importante referir que este exame foi alvo de inúmeros debates e reflexões da área acerca da sua adequação como instrumento avaliativo da qualidade do ensino, bem como da efetiva contribuição de tal instrumento para a melhoria da qualidade dos cursos. 


\section{temporollis}

Em 2006, iniciou-se a oferta da modalidade do ensino a distância na área (portanto, há dez anos), o que, sem dúvida, foi o aspecto desencadeador de um conjunto de movimentos da categoria para evitar a sua institucionalização, pois são sabidas as razões pelas quais a profissão se posiciona de forma contrária à sua oferta. No que tange à operacionalização dessa modalidade de ensino, Pereira (2008) afirmou que, no âmbito da formação profissional, depois de quase uma década de debates e da aprovação das DCs, pouco se conhecia (e ainda se conhece) sobre as condições concretas desse modelo para a efetiva formação dos profissionais. Destacava, naquela ocasião, a necessidade de radiografar um perfil de tais cursos, para apreender a forma e as características da expansão do ensino a distância em Serviço Social no País. Neste mesmo ano, a ABEPSS empreendeu uma pesquisa, de âmbito nacional, que avaliou o processo de implementação das DCs na área, durante o ano de 2006, após dez anos de sua aprovação no âmbito profissional, e que se constituiu em um insumo fundamental para a apreensão do estágio destas no interior das UFAs as quais participaram da referida pesquisa. Ao mesmo tempo, subsidiou a categoria na identificação das condições e tendências da implementação das DCs nas mesmas e na revisão das estratégias para avançar no seu enraizamento, cabendo citar que a sistematização e a reflexão acerca dos resultados desta pesquisa se encontram na edição 14 da Revista Temporalis. (ABEPSS, 2007).

Em 2007, numa tentativa de resistir ao avanço da oferta massiva de vagas para o curso, nas modalidades a distância e presencial, o que, no seu conjunto, anunciava uma possível queda na qualidade e impactos no mercado de trabalho, a categoria debateu o exame de proficiência como uma tática de defesa do projeto político, gerando posições contrárias (e igualmente polêmicas) na sua defesa, que culminaram com o consenso de que o referido exame não se constituiria na melhor estratégia (BOSCHETTI, 2008; RODRIGUES, 2008). Nessa mesma direção, o conjunto ABEPSS/CFESS/CRESS/ENESSO lançou o posicionamento das entidades nacionais de Serviço Social sobre criação e proliferação de cursos de graduação a distância, a fim de publicizar sua posição acerca desta modalidade de ensino. Nesse ano, a área possuía 74.521 assistentes sociais inscritos nos Conselhos Regionais e participou do $2^{\circ}$ ENADE. O CFESS encaminhou aos Conselhos Regionais o parecer jurídico de $n^{\circ} 10 / 2007$, alertando para a fiscalização dos requisitos obrigatórios na validação dos cursos de Graduação em Serviço Social a Distância e os procedimentos que deveriam ser adotados 


\section{tempordis}

para a qualidade dos serviços prestados à sociedade pelos concluintes de tais cursos.

Neste contexto, a questão dos estágios e da supervisão passou a ser alvo de reflexão da categoria, tendo em vista que os requisitos indispensáveis ao processo de supervisão não estavam sendo cumpridos (especialmente pelas UFAs da modalidade a distância, mas não exclusivamente). Em 2008 como resposta para esta realidade, o CFESS aprovou a Resolução $n^{\circ} 533 / 2008$, que regulamentou a supervisão direta de estágio no Serviço Social. Esse documento teve forte impacto no âmbito da formação e do exercício profissional, gerando questionamentos, dúvidas e polêmicas, principalmente no que concerne à concepção de supervisão direta. Destaca-se esta concepção com mais ênfase, visto que foi uma das resoluções mais polêmicas do período e cuja resistência na sua adoção ainda persiste pelas dificuldades institucionais de todos os sujeitos envolvidos com este processo. Sua repercussão foi muito expressiva, pois impactou no comportamento dos profissionais que exerciam a atribuição de supervisor de campo, especialmente no alinhamento do número de alunos por supervisores, na redução de vagas nos campos, e até mesmo no fechamento de alguns.

Em 2009, foi elaborada Carta Aberta aos Estudantes e TrabaIhadores dos Cursos de Graduação a Distância em Serviço Social no Brasil, durante o $38^{\circ}$ Encontro Nacional do Conjunto CFESS/CRESS, com o objetivo de esclarecer o posicionamento da categoria acerca desta modalidade de ensino e evitar a culpabilização dos sujeitos que dela participam. Neste mesmo ano, foi aprovado o Plano de Lutas em defesa do Trabalho e da Formação e Contra a Precarização do Ensino Superior do conjunto, que apresentou uma combinação de ações, no âmbito da formação e do exercício profissional, alinhadas com a busca pela garantia da qualidade do ensino/supervisão.

Concomitantemente, o Plano de Trabalho da Gestão 2009-2010 da ABEPSS incluiu a luta contra a precarização e o aligeiramento do ensino, especialmente na modalidade a distância, como compromisso orientador geral dessa gestão.

E em 2010, a ABEPSS concluiu, através de um intenso trabalho coletivo, a elaboração da Política Nacional de Estágio (PNE ${ }^{4}$ ), iniciada

4 Esse trabalho envolveu: a) os resultados da pesquisa avaliativa sobre a 


\section{temporalis}

em 2009. Diante de um cenário de precarização do ensino superior e de expansão do ensino a distância, tal ação foi uma resposta da categoria, além de atender a uma demanda histórica do Serviço Social no que se refere a uma orientação mais clara quanto à natureza do estágio curricular. $\mathrm{E}$, especialmente, no que tange aos papéis e atribuições de cada sujeito participante do processo de supervisão (RAMOS, 2009), para questões referentes ao estágio curricular não obrigatório, ancorado na Lei n. 11.788/2008, bem como às relacionadas ao estágio curricular obrigatório. Nesse sentido, a PNE é fundamental na orientação e organização dos princípios e conteúdos formativos do estágio em Serviço Social. O grande desafio passa a ser sua socialização e enraizamento no interior das UFAs, pela importância estratégica de reafirmar as diretrizes curriculares.

Ainda em 2010, o CFESS lançou, a fim de subsidiar o debate da categoria profissional, o primeiro volume do documento intitulado "Sobre a incompatibilidade entre graduação a distância e Serviço Social" com a intenção de traçar um panorama da adoção dessa modalidade de ensino, apresentando os dados coletados pelos Conselhos Regionais de Serviço Social (CRESS5) de todo o País, em suas atividades de fiscalização do exercício profissional, seus rebatimentos na qualidade da formação pela oportunidade de apresentação desta lógica de expansão e o perfil do ensino superior brasileiro nas duas últimas décadas, problematizando o EAD como estratégia e as razões pelas quais o órgão se opunha à oferta deste modelo para a área, pela ancoragem na legislação profissional, especialmente a Resolução $n^{\circ}$ 533/2008(CFESS, 2008), e a Lei de Regulamentação da Profissão (Lei $\left.n^{\circ} 8662 / 1993\right)$. Entende-se que esta produção foi muito contributiva, tendo em vista a dificuldade em acessar dados sobre esta proposta de ensino e pela sua valiosa publicização.

Em 2011, o CFESS empreendeu uma grande conquista no âmbito do exercício profissional com a luta para a aprovação e publicação da Lei $n^{\circ} 12.317$, de 26 de agosto de 2010, que estabeleceu a jornada

implementação das DCs, apontando a necessidade de elaboração de uma Política Nacional de Estágio, realizadas nas gestões 2005-2008 da ABEPSS; b) debates ocorridos no país em oitenta eventos, abrangendo 175 UFAS e 4.445 participantes; c) encaminhamentos resultantes das seis Oficinas Regionais de Graduação da ABEPSS; c) propostas enviadas da Oficina Nacional de Graduação realizada no Rio de Janeiro, em novembro de 2009. (ABEPSS, 2009).

5 Os CRESS são organizados por estados e o Distrito Federal, somando atualmente, vinte e seis Conselhos Regionais e uma seccional de base estadual. 


\section{tempordis}

de trabalho de 30 horas semanais para assistentes sociais, num claro esforço em garantir qualidade ao trabalho dos profissionais. É importante destacar que o Conselho Federal vem recebendo manifestações de reconhecimento da importância dessa conquista e, ainda, informações sobre a implementação da lei em diversas instituições públicas, privadas, ONGs, filantrópicas entre outras, que se materializa e se amplia dia após dia (CFESS, 2011). Além disso, foi criado o Observatório das 30 horas, no qual são divulgadas, sistematicamente, informações importantes sobre as ações efetivadas pelo Conjunto CFESS/CRESS em defesa da lei (CFESS, 2011).

Neste mesmo ano de 2011, ocorreu a reedição pelo CFESS/ CRESS/ENESSO/ABEPSS do documento intitulado "Sobre a incompatibilidade entre graduação a distância e Serviço Social" acompanhada da campanha em defesa da formação de qualidade "Educação não é fast food: diga não para a graduação a distância em Serviço Social". Ambos os documentos tiveram sua circulação proibida por determinação judicial, revelando que, se por um lado a informação não pôde ser socializada, por ordem judicial, por outro, foi inegável a potência desta campanha em chamar atenção da comunidade acadêmica e da sociedade em geral, evidenciando a força da categoria em utilizar estratégias de comunicação como forma de publicização da realidade da formação na área.

No cenário brasileiro, segundo dados do Censo da Educação Superior (MEC), neste mesmo ano, o número de matrículas nos cursos de Serviço Social chegou a 143.198, sendo 109.663 em UFAs privadas (75\%) e 33.535 em UFAs públicas (25\%). Destas matrículas, 56.815 se referiam à modalidade a distância (52\%) e 52.848 à modalidade presencial (48\%). O número de concluintes foi de 20.017 alunos, sendo 9.287 na modalidade presencial (46\%) e 8.925 na modalidade a distância (44\%). (MEC, 2014).

Considerando que a participação privada, desde a gênese do Serviço Social, detém a hegemonia na oferta do curso, torna-se necessário destacar a participação pública e a nova modalidade: a público-privada, que se materializou no Programa Universidade para Todos (PROUNI), criado em 2004 pela Medida Provisória $n^{\circ}$ 213, e institucionalizado pela Lei $n^{\circ} 11.096$, de 13 de janeiro de 2005. Apresenta esse Programa, como finalidade, a concessão de bolsas de estudos de dois tipos: parciais ou integrais, para estudantes de cursos de graduação e sequenciais de formação específica, em Instituições privadas de Ensi- 


\section{temporalis}

no Superior, com ou sem fins lucrativos, oferecendo dispensa legal de alguns tributos, em compensação àquelas que aderirem ao Programa. Até 2013, data dos dados mais recentes (MEC, 2014), haviam sido concedidas 252.374 bolsas para todos os cursos de graduação (164.379 integrais e 87.995 parciais). Ambas as iniciativas apresentaram um traço contínuo: o predomínio dessa oferta em instituições privadas e a diversificação das modalidades de ensino em várias áreas. Igualmente, na esfera pública, se ressalta o Programa de Apoio aos Planos de Reestruturação e Expansão das Universidades Federais (REUNI), instituído em 2007, com o Decreto $\mathrm{n}^{\circ} 6.096$, em atendimento ao disposto pelo Plano Nacional de Educação (2001/2010), que estabelecia o provimento da oferta da educação superior para, pelo menos, $30 \%$ dos jovens na faixa etária de 18 a 24 anos, até o final da década. ${ }^{6}$

Segundo dados do CFESS, obtidos no site da entidade, o contingente profissional indicava nesse ano (2011) 110.000 assistentes sociais, o que significa que, pela primeira vez na história da profissão, o número de alunos superou o de profissionais, o que impõe o debate acerca da necessidade da oferta de vagas para o curso, na sua relação com o mercado de trabalho. Em outras palavras: o Brasil necessita desse contingente profissional ou esse contingente atende, majoritariamente, aos interesses privados e exclusivos de comercialização da educação superior?

No compasso dessa ampliação do contingente profissional e da necessidade em qualificar a formação, avançando no processo de enraizamento das DCs, a ABEPSS lançou, em 2012, a primeira edição do projeto e da experiência intitulada "ABEPSS Itinerante - A Atualidade do Projeto de Formação Profissional frente a contrarreforma da Educação", com formato de curso de aperfeiçoamento, objetivando o fortalecimento das estratégias político-pedagógicas de enfrentamento à precarização do ensino superior, por meio da difusão ampla dos princípios, conteúdos e desafios colocados para a consolidação das DCs como instrumento fundamental na formação de novos profissionais (ABREU, 2013). O projeto alcançou todas as regiões brasileiras, articulando diversas UFAs, que se comprometeram, em sua maioria, com a socialização e multiplicação da proposta, traduzindo uma im-

6 No ano de 2010, a título de ilustração, foram oferecidas 218.152 vagas presenciais, em todos os cursos de graduação, em universidades públicas federais, revelando um incremento de mais de 80 mil vagas no período posterior à implantação do REUNI nas referidas universidades. (MEC, 2014). 


\section{tempordilis}

portante ação da categoria na direção da capacitação profissional, e como estratégia na defesa da formação profissional consubstanciada nas Diretrizes Curriculares conforme atesta a edição 25 da Revista Temporalis (TEMPORALIS, 2013).

Em 2013, consolidou-se a Política de Educação Permanente do conjunto CFESS e CRESS, fruto de muita discussão e trabalho coletivo, das gestões "Tempo de Luta e Resistência" (2011-2014), e da gestão "Atitude crítica para avançar na Luta" (2008-2011), bem como com as contribuições da Associação Brasileira de Ensino e Pesquisa em Serviço Social (ABEPSS) e da Executiva Nacional de Estudantes de Serviço Social (ENESSO) e aprovada no $40^{\circ}$ Encontro Nacional do CFESS/ CRESS, que condensa mais uma estratégia da categoria em garantir o Projeto Profissional e, ao mesmo tempo, aponta as mediações para a sua efetivação. Nesse mesmo ano, a área realizou a $4^{\mathrm{a}}$ edição do ENADE, exame que constitui uma polêmica no debate acerca da formação, com referência a sua prática (já comentada anteriormente), mas aqui explorada no aspecto referente ao desempenho dos cursos. É importante que reconheçamos que a noção de qualidade presente em instrumentos como o ENADE traduz uma lógica que reproduz o modelo gerencial empresarial assumido pelo Estado, na sua função reguladora, uma vez que ranqueia as UFAs, bem como se restringe a indicadores quantitativos. Ainda assim, é um instrumento privilegiado, que nos permite analisar este aspecto na área. Recorrendo ao desempenho registrado nas quatro execuções do exame, sistematizamos as informações a seguir indicadas:

Quadro 1: Ano, Número de cursos e de estudantes, Conceitos obtidos no ENADE pela área de Serviço Social (Período 2004 a 2013)

\begin{tabular}{|l|r|r|r|r|}
\hline $\begin{array}{c}\text { Ano/Cursos/ } \\
\text { Estudantes/ } \\
\text { Conceitos }\end{array}$ & 2004 & $\mathbf{2 0 0 7}$ & $\mathbf{2 0 1 0}$ & $\mathbf{2 0 1 3}$ \\
& & & & \\
\hline Total de Cursos & 134 & $\mathbf{2 3 6}$ & $\mathbf{2 9 7}$ & $\mathbf{2 8 2}$ \\
Cursos Privados & 100 & 192 & 241 & 221 \\
Cursos Públicos & 34 & 44 & 56 & 57 \\
\hline
\end{tabular}




\section{tempordils}

\begin{tabular}{|c|c|c|c|c|}
\hline $\begin{array}{l}\text { Total de Estudantes } \\
\text { Ingressantes } \\
\text { Concluintes }\end{array}$ & $\begin{array}{l}\mathbf{1 4 . 1 3 2} \\
9041 \\
5091\end{array}$ & $\begin{array}{c}50.697 \\
42921 \\
7776\end{array}$ & $\begin{array}{l}48.304 \\
24244 \\
24060\end{array}$ & $\begin{array}{l}30.857 \\
----7 \\
30857\end{array}$ \\
\hline $\begin{array}{l}\text { Conceitos Obtidos } \\
1\end{array}$ & $\begin{array}{l}13 \quad 7 \\
\text { Públicas }\end{array}$ & 107 públicas & $\begin{array}{l}13 \quad 9 \\
\text { públicas }\end{array}$ & 65 públicas \\
\hline 2 & $\begin{array}{l}14 \\
\text { Públicas }\end{array}$ & 62 públicas & $\begin{array}{lr}8 & 4 \\
\text { públicas }\end{array}$ & 538 públicas \\
\hline 3 & 20 & 25 & 52 & 139 \\
\hline 4 & 42 & 84 & 118 & 67 \\
\hline 5 & 4 & 8 & 28 & 11 \\
\hline Sem Conceito & 41 & 103 & 78 & 6 \\
\hline
\end{tabular}

Fonte: Sistematizado pelo Grupo de Pesquisa Formass/PUCRS, com base nos Relatórios Síntese do Serviço Social no ENADE (MEC, 2004-2013).

Os dados do Quadro 1 confirmam a expansão no número de cursos de Serviço Social, especialmente no ano de 2007, período histórico que coincidiu com o início da oferta do curso na modalidade a distância (2006). Destaca-se o número de alunos, que chegou a mais de 50 mil, sendo significativo o número de ingressantes nesse mesmo ano, assim como o de concluintes (nas edições de 2010 e 2013): mais de 55 mil alunos foram colocados no mercado de trabalho, ou seja, cerca de $45 \%$ do contingente profissional atual. Em face desse quantitativo, urge instaurar o debate sobre a qualidade desta formação, expressa na queda das notas, as quais traduzem o resultado final da avaliação do desempenho dos cursos, lembrando que o conceito máximo é 5 e que notas obtidas entre 1 e 3 demandam a realização de visitas por parte do órgão regulador. Conclui-se que o maior desempenho conseguido pela área ocorreu no ano de 2010, com 49\% de notas 4 e 5 , sendo que, nos anos de 2004 e 2007, o desempenho foi, respectivamente, de 34 e $38 \%$. Entretanto, chama a atenção a queda no desempenho da área no último exame, quando esse percentual chegou a $27 \%$ nos conceitos 4 e 5 , o que indica um comprometimento da qualidade, pois 198 cursos, ou seja, 70\%, obtiveram notas entre 1 e 3. Ressalta-se que, contraditoriamente, esta é uma área que oferta majoritariamente cursos privados, sendo inegável o excelente desempenho dos cursos públicos na obtenção do conceito 5, nas 4 edições

7 Em 2013, o ENADE foi aplicado somente aos estudantes concluintes, por isso não foram informados os dados dos ingressantes. 


\section{tempordils}

do exame, o que sinaliza que cursar esta formação em uma estrutura dessa natureza ainda se constitui num diferencial de qualidade. Por outro lado, destaca-se que, em muitas delas, o movimento estudantil procedeu a sucessivos boicotes, o que "mascara" o desempenho final de boa parte das públicas.

Outro dado extraído do referido relatório-síntese refere-se ao perfil dos alunos, pois, de um universo constituído por 30.857 inscritos, $91,9 \%$ eram do sexo feminino e $8,1 \%$ do sexo masculino; $42,3 \%$ se encontravam na faixa etária acima dos 35 anos e $21,2 \%$ se encontravam na faixa entre 25 e 29 anos de idade; $44,1 \%$ se declararam pardos ou mulatos, $40,3 \%$ brancos, $13,4 \%$ negros, $1,4 \%$ amarelos e $0,9 \%$ indígenas. Com relação a renda, $27,4 \%$ tinham renda e contribuíam para o sustento da família; $26 \%$ não tinham renda e seus gastos eram financiados pela família ou outras pessoas; $24,1 \%$ tinham renda, mas recebiam ajuda da família ou de outras pessoas; $10,4 \%$ tinham renda e não precisavam de ajuda para financiar os estudos; 3\% não tinham renda e seus gastos eram financiados por programas governamentais. A média salarial dos alunos oscilou entre 1,5 e 3 salários-mínimos na faixa dos $35,4 \%$, e até 1,5 salários-mínimos na faixa dos $30,8 \%$. No seu conjunto, esses dados nos permitem constatar que o aluno atual de Serviço Social pertence às camadas populares, com renda de até 3 salários-mínimos (65\%); um percentual de $57 \%$ se declarou negro, pardo ou mulato; o predomínio é da presença feminina e, na sua maioria, com idade superior ao ideal para ingresso nesse nível de ensino (42,5\% possuem mais de 35 anos de idade).

Dando continuidade à trajetória histórica, o CFESS lançou, no ano de 2014, como mais uma estratégia de garantia da qualidade da formação, o documento intitulado "Meia formação não garante um direito: o que você precisa saber sobre a supervisão de estágio direta em Serviço Social". Disponibilizou, dessa maneira, para estudantes e assistentes sociais, CRESS e responsáveis pela supervisão (acadêmica e de campo) um conjunto de informações para consulta que reúne as determinações legais e normativas acerca da supervisão direta de estágio em Serviço Social, tendo em vista as requisições profissionais, no que se refere: a) credenciamento de campo de estágio, b) o número de estagiários/as por profissional; c) aplicação de multas; d) garantias éticas e técnicas para o exercício profissional do/a supervisor/a. Essas são questões que vêm exigindo na perspectiva da Política de Fiscalização (PNF) do Conjunto CFESS/CRESS, tanto as ações político-pedagógica, quanto as orientações normativo-disciplinado- 


\section{temporolis}

ras. Nesse mesmo ano de 2014, a ABEPSS lançou a segunda edição do projeto intitulado "ABEPSS ITINERANTE - ESTÁGIO SUPERVISIONADO EM SERVIÇO SOCIAL: desfazendo os nós e construindo alternativas", com o objetivo de fortalecer a implementação da Política Nacional de Estágio (PNE) como estratégia para a ampliação da base político-acadêmica do plano de lutas em defesa do trabalho e da formação e contra a precarização do ensino superior, nas UFAs. O produto desta experiência resulta no relato das principais recomendações e encaminhamentos construídos durante o processo das oficinas, no qual são apresentados os nós críticos no que se refere ao debate da unidade teoria e prática, bem como as estratégias para os enfrentamentos dos nós críticos no processo do estágio supervisionado em Serviço Social. Os resultados construídos nas oficinas estão expostos na edição 31 da Revista Temporalis (TEMPORALIS, 2016), na perspectiva de dar visibilidade sobre as experiências que vêm contribuindo na consolidação de estratégias permanentes de descentralização da ABEPSS; da comunicação com as UFAS; no enfrentamento da precarização do ensino superior, através de amplo debate e incentivo à consolidação das Diretrizes Curriculares e de fortalecimento à implementação da PNE.

A configuração atual da formação, a partir de uma atualização dos dados quantitativos da área, em uma pesquisa feita no site do eMEC em maio de 2016, indica que o universo de UFAs é de 394 instituições, sendo que $224(56,8 \%)$ são Faculdades, 111 (28,1\%) são Universidades, 58 (14,7\%) são Centros Universitários e 1 (0,2\%) é vinculada a um Instituto Federal de Educação, Ciência e Tecnologia. Deste universo, 366 (92,8\%) ofertam o curso na modalidade presencial, 22 (5,5\%) ofertam o curso na modalidade presencial e a distância e 4 (1\%) a distância (o que não inclui o número de polos). O número de mantenedoras dessas UFAs é de 335 (85\%), sendo 171 IES com fins lucrativos e 162 IES sem fins lucrativos (destas, 33 são filantrópicas). Quanto às públicas, 34 são federais, 16 estaduais e 11 municipais. No que se refere à distribuição das UFAs por modalidade de ensino, o quadro a seguir indica a sua distribuição. (e-MEC, 2016).

Quadro 2: Distribuição das UFAS por Modalidade de Ensino e Natureza

\begin{tabular}{|l|l|l|}
\hline \multicolumn{1}{|c|}{ PRESENCIAL } & \multicolumn{1}{|c|}{ A DISTÂNCIA } & $\begin{array}{c}\text { PRESENCIALE A } \\
\text { DISTÂNCIA }\end{array}$ \\
\hline 366 UFAs & 6 UFAs & 22 UFAs \\
\hline
\end{tabular}




\begin{tabular}{|c|c|c|}
\hline $\begin{array}{l}94 \text { Universidades } \\
47 \text { Centros Universitários } \\
224 \text { Faculdades } \\
1 \text { Instituto Federal }\end{array}$ & $\begin{array}{l}2 \text { Universidades } \\
4 \text { Centros Universitários }\end{array}$ & $\begin{array}{l}15 \text { Universidades } \\
7 \text { Centros } \\
\text { Universitários }\end{array}$ \\
\hline $\begin{array}{l}\text { NATUREZA DAS UFAS } \\
\text { PRESENCIAIS }\end{array}$ & $\begin{array}{l}\text { NATUREZA DAS UFAs A } \\
\text { DISTÂNCIA }\end{array}$ & $\begin{array}{c}\text { NATUREZA DAS } \\
\text { UFAS COM A } \\
\text { MODALIDADE } \\
\text { PRESENCIAL E A } \\
\text { DISTÂNCIA }\end{array}$ \\
\hline $\begin{array}{l}34 \text { Públicas Federal } \\
16 \text { Públicas Estadual } \\
11 \text { Públicas Municipal } \\
152 \text { Privadas sem fins } \\
\text { lucrativos } \\
153 \text { Privadas com fins } \\
\text { lucrativos }\end{array}$ & $\begin{array}{l}3 \text { Privadas sem fins lucrativos } \\
3 \text { Privadas com fins lucrativos }\end{array}$ & $\begin{array}{l}7 \text { Privadas sem fins } \\
\text { lucrativos } \\
15 \text { Privadas com fins } \\
\text { lucrativos }\end{array}$ \\
\hline
\end{tabular}

Fonte: Sistematizado pelo Grupo de Pesquisa FORMASS/PUCRS, adaptado de eMEC (2016).

Outro dado relevante, nesta conformação, é o dos grupos educacionais que passam a deter a hegemonia da oferta do curso, especialmente, na modalidade a distância na área, a saber: 1) a Kroton Educacional tornou-se uma das maiores organizações educacionais privadas do Brasil, agregando as instituições de ensino Anhanguera, Pitágoras, Fama, Universidade do Norte do Paraná (UNOPAR), Universidade de Cuiabá (UNIC), União Metropolitana de Educação e Cultura (UNIME), entre outras. Identificamos, no mapeamento feito no período citado, 25 UFAs que pertencem a este grupo; 2) o Grupo Ser Educacional agrega as instituições de ensino Universidade da Amazônia (UNAMA), Universidade de Guarulhos (UNG), Faculdades Maurício de Nassau (UNINASSAU, NASSAU), Faculdade de Juazeiro do Norte (FJN) e Faculdade de Itapecerica da Serra (FIT), que juntas possuem 18 UFAs. Este processo evidencia o movimento do mercado, em aglutinar IES que antes se encontravam isoladas e passaram a fazer parte de monopólios de serviços educativos a distância, os quais incluem o curso de Serviço Social. Por fim, cabe atualizar o dado acerca do contingente profissional que, conforme informação verbal dada pelo Presidente do CFESS, durante a mesa de abertura do XV Congresso Brasileiro de Assistentes Sociais, ocorrido em Olinda, entre os dias 5 e 9 de setembro de 2016, atingiu o número de 170 mil profissionais.

Os dados e fatos históricos evidenciam o quanto as duas últi- 


\section{temporalis}

mas décadas trouxeram mudanças estruturais na política de educação superior no nosso país que podem ser sintetizadas num movimento de contrarreforma do Estado, com uma tensa disputa pela noção de "público" e de "direito" no acesso a esse nível de ensino. Esta afirmação se materializa com base nos dados que evidenciam estarmos diante de um modelo de Estado que vem promovendo a reforma universitária "aos pedaços", mediante a expansão da educação superior como mercadoria, portanto estimulando a participação da iniciativa privada e com ela formalizando parcerias. Fomenta, assim, de forma massiva, a modalidade de ensino a distância e se institucionaliza como um Estado majoritariamente regulador e pouco executor, o que se alinha ao ideário neoliberal, presente nos movimentos de contrarreforma do Estado no âmbito mundial e, consequentemente, nacional. Ressalta-se, no entanto, que esse processo foi acompanhado por importantes movimentos da categoria profissional que revelam a sua capacidade de apreensão desta política, bem como de construção de estratégias de resistência alinhadas com a defesa e garantia do projeto de formação construído em 1996. No quadro a seguir, o leitor poderá visualizar uma síntese do período histórico que, neste artigo, procuramos resgatar e significar, a fim de registrar o legado dessas duas décadas.

Quadro 3: Ano, Regulações no âmbito da política de educação superior e ações da Profissão no campo da resistência na defesa da formação e do exercício profissional ${ }^{8}$

\begin{tabular}{|c|l|c|}
\hline Ano & $\begin{array}{c}\text { Regulação do Estado/Mercado } \\
\text { na Política de Educação superior }\end{array}$ & $\begin{array}{c}\text { Ações da Profissão no campo } \\
\text { da resistência na defesa da } \\
\text { formação e do exercício } \\
\text { profissional }\end{array}$ \\
\hline 1996 & $\begin{array}{l}\text { Governo Fernando Henrique } \\
\text { Cardoso } \\
\text { Lei de Diretrizes e Bases da } \\
\text { Educação (LDB) }\end{array}$ & \begin{tabular}{c} 
Diretrizes Curriculares (ABESS) \\
\hline
\end{tabular} \\
\hline
\end{tabular}

8 Fonte: Sistematizado pelo Grupo de Pesquisa Formass/PUCRS e Gefess/UFRGS com base na pesquisa bibliográfica e documental, tendo como fonte as produções da área, os documentos da profissão e dados obtidos no site do MEC e e-Mec (2016). 


\begin{tabular}{|c|c|c|}
\hline 1998 & $\begin{array}{l}\text { LDB - decretos e portarias do MEC } \\
\text { que a regulamentam começou a } \\
\text { ser publicada em 1998. EAD em } \\
\text { pauta / Cursos Sequenciais. }\end{array}$ & 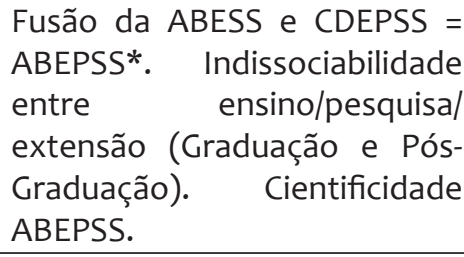 \\
\hline 1999 & $\begin{array}{l}\text { Declaração de Bolonha } \\
\text { (Comunidade Europeia) e } \\
\text { Documento do Banco Mundial } \\
\text { sobre Educação na América } \\
\text { Latina e Caribe incidem no início } \\
\text { de um processo hegemônico } \\
\text { de desregulamentação e } \\
\text { flexibilização que orienta a } \\
\text { política governamental no ensino } \\
\text { superior. }\end{array}$ & $\begin{array}{l}\text { Plano de Lutas - Debates } \\
\text { críticos. } \\
\text { Tema: Política do Ensino } \\
\text { Superior no Brasil: } \\
\text { regulamentação da LDB e } \\
\text { implicações para o Serviço } \\
\text { Social. Seminário Nacional; } \\
\text { Comissão (cursos sequenciais); } \\
\text { mapeamento (situação das } \\
\text { UFAS) Oficinas Regionais } \\
\text { Locais. } \\
1^{\circ} \text { curso de especialização em } \\
\text { Serviço Social e Política Social. }\end{array}$ \\
\hline 2000 & $\begin{array}{l}\text { Declaração dos EUA na reunião } \\
\text { da OMC formalizando a noção de } \\
\text { educação como serviço, portanto, } \\
\text { passível de comercialização. }\end{array}$ & $\begin{array}{l}\text { Editoração da Revista } \\
\text { Temporalis em substituição } \\
\text { aos cadernos ABESS. }\end{array}$ \\
\hline Ano & $\begin{array}{l}\text { Regulação do Estado/Mercado } \\
\text { na Política de Educação superior }\end{array}$ & $\begin{array}{c}\text { Ações da Profissão no campo } \\
\text { da resistência na defesa da } \\
\text { formação e do exercício } \\
\text { profissional }\end{array}$ \\
\hline 2002 & $\begin{array}{l}\text { Aprovação das DCs pelo MEC, } \\
\text { marcada pela supressão/ } \\
\text { desconfiguração do texto original } \\
\text { encaminhado pela Comissão de } \\
\text { especialistas da área. Mantém- } \\
\text { se, contudo, a unidade História, } \\
\text { Teoria e Método, alicerçando a } \\
\text { noção da profissão como uma } \\
\text { totalidade histórica. }\end{array}$ & $\begin{array}{l}\text { ABEPSS passa a interferir nos } \\
\text { parâmetros e no processo } \\
\text { de avaliação institucional dos } \\
\text { Cursos de Serviço Social. }\end{array}$ \\
\hline
\end{tabular}




\section{temporollis}

\begin{tabular}{|c|c|c|}
\hline 2003 & $\begin{array}{l}\text { Governo Luis Inácio Lula da Silva } \\
\text { Parecer autorizando os cursos do } \\
\text { ensino a distância na graduação; } \\
\text { Realização do } 1^{\circ} \text { ENADE na área } \\
\text { Conferência Mundial da Unesco }\end{array}$ & $\begin{array}{l}\text { Tentativa de redução da carga } \\
\text { horária mínima dos cursos de } \\
\text { Serviço Social (de } 3.200 \mathrm{~h} / \mathrm{a} \\
\text { para } 2.400 \mathrm{~h} / \mathrm{a} \text { ) que, mediante a } \\
\text { mobilização nacional (ABEPSS, } \\
\text { Cefess, ENESSO) resultou, na } \\
\text { aprovação pelo CNE, de uma } \\
\text { resolução que definiu a carga } \\
\text { horária mínima em } 3.000 \mathrm{~h} / \mathrm{a} \text {. }\end{array}$ \\
\hline 2004 & $\begin{array}{l}\text { Projeto de reforma universitária } \\
\text { (1 }{ }^{a} \text { versão) - "Reforma aos } \\
\text { Pedaços"; Política de Cotas; } \\
\text { autorização da modalidade } \\
\text { semipresencial na Graduação } \\
\text { (até } 20 \% \text { da carga horária total do } \\
\text { curso); Sinaes; Prouni. }\end{array}$ & $\begin{array}{l}\text { Pesquisa Nacional sobre o } \\
\text { Perfil do Assistente Social no } \\
\text { Brasil (CFESS). }\end{array}$ \\
\hline 2006 & $\begin{array}{l}\text { Início da oferta dos primeiros } \\
\text { cursos de graduação a distância } \\
\text { no Serviço Social }\end{array}$ & $\begin{array}{l}\text { Pesquisa avaliativa sobre a } \\
\text { implantação das DCs pela } \\
\text { ABEPSS; } \\
\text { Resolução CFESS } 493 / 2006 \\
\text { sobre as condições éticas } \\
\text { e técnicas do exercício } \\
\text { profissional; } \\
249 \text { UFAs (Maciel, 2006) }\end{array}$ \\
\hline 2007 & $\begin{array}{l}\text { Reuni; PNAES; Referenciais } \\
\text { de qualidade para o ensino à } \\
\text { distância no país; Realização do } 2^{\circ} \\
\text { ENADE na área }\end{array}$ & $\begin{array}{l}\text { Parecer jurídico de } n^{\circ} \text { 10/07 } \\
\text { (CFESS); } \\
\text { Exame de proficiência; } \\
\text { Posicionamento das entidades } \\
\text { sobre criação e proliferação } \\
\text { de cursos de graduação a } \\
\text { distância }\end{array}$ \\
\hline
\end{tabular}




\begin{tabular}{|c|c|c|}
\hline 2008 & $\begin{array}{l}\text { Lei Nacional dos Estágios }\left(\mathrm{n}^{\circ}\right. \\
11.788 \text { ) } \\
\text { Expansão do número de } \\
\text { alunos na Universidade do } \\
\text { Tocantins (Unitins), seguido pela } \\
\text { Universidade Norte do Paraná } \\
\text { (Unopar) (MEC-INEP, 2008) }\end{array}$ & $\begin{array}{l}\text { Resolução } n^{\circ} 533 / 2008 \text { que } \\
\text { regulamentou a supervisão } \\
\text { direta de estágio no Serviço } \\
\text { Social; } \\
\text { Relatório Final da Pesquisa } \\
\text { Avaliativa sobre as DCS feita } \\
\text { em } 2006 \text {. } \\
\text { Denúncia pelo conjunto CFESS/ } \\
\text { CRESS das irregularidades } \\
\text { levaram o MEC a acatar a } \\
\text { recomendação do Ministério } \\
\text { Público Federal de suspender } \\
\text { as atividades de EAD da Unitins } \\
\text { (Cf. CFESS/CRESS, ABEPSS, } \\
\text { ENESSO, 2010). }\end{array}$ \\
\hline 2009 & Conferência Mundial Unesco & $\begin{array}{l}\text { Política Nacional de Estágios } \\
\text { (ABEPSS); } \\
\text { Carta Aberta aos Estudantes } \\
\text { e Trabalhadores dos Cursos } \\
\text { de Graduação a Distância } \\
\text { em Serviço Social no Brasil; } \\
\text { - Plano de Lutas em Defesa } \\
\text { do Trabalho e da Formação } \\
\text { e Contra a Precarização do } \\
\text { Ensino Superior; } \\
\text { ABEPSS incluiu a luta contra a } \\
\text { precarização e o aligeiramento } \\
\text { do ensino, especialmente, na } \\
\text { modalidade a distância. } \\
\text { II Curso de Especialização lato } \\
\text { sensu em SS: Direitos Sociais } \\
\text { e Competências profissionais } \\
\text { (CFESS). }\end{array}$ \\
\hline Ano & $\begin{array}{l}\text { Regulação do Estado/Mercado } \\
\text { na Política de Educação superior }\end{array}$ & $\begin{array}{c}\text { Ações da Profissão no campo } \\
\text { da resistência na defesa da } \\
\text { formação e do exercício } \\
\text { profissional }\end{array}$ \\
\hline
\end{tabular}




\begin{tabular}{|c|c|c|}
\hline 2010 & $\begin{array}{l}\text { Realização do } 3^{\circ} \text { ENADE na área; } \\
\text { Descredenciamento, termos de } \\
\text { saneamento e/ou fechamento de } \\
\text { UFAs a distância na área. }\end{array}$ & $\begin{array}{l}\text { Estruturação dos Grupos } \\
\text { Temáticos de Pesquisa-GTPS/ } \\
\text { ABEPSS- Demanda desde } \\
\text { o final da década de } 1990 . \\
\text { Pensado e construído como } \\
\text { uma estratégia coletiva de } \\
\text { fortalecimento da pesquisa } \\
\text { na área de SS, bem como } \\
\text { de resistência contra o } \\
\text { produtivismo, a pressão e o } \\
\text { isolamento dos pesquisadores, } \\
\text { mediante a coletivização dos } \\
\text { debates de ponta indicação } \\
\text { dos temas relevantes para a } \\
\text { área. }\end{array}$ \\
\hline 2011 & $\begin{array}{l}\text { Governo Dilma Roussef } \\
\text { Plano Nacional de Pós-Graduação } \\
2011-2020 \\
\text { Censo da Educação Superior } \\
\text { (INEP/MEC) } \\
\text { Realização do } 3^{\circ} \text { ENADE na área }\end{array}$ & $\begin{array}{l}\text { Aprovação da Lei } n^{\circ} 2.317 \text { (30 } \\
\text { horas de trabalho) } \\
\text { Conjunto lança o documento } \\
\text { "Sobre a incompatibilidade } \\
\text { entre graduação a distância e } \\
\text { Serviço Social" e a campanha } \\
\text { em defesa da formação de } \\
\text { qualidade "Educação não } \\
\text { é fast-food: diga não para } \\
\text { a graduação à distância em } \\
\text { Serviço Social" } \\
358 \text { UFAS (lamamoto, 2014) }\end{array}$ \\
\hline 2012 & Programa Ciência sem Fronteiras & $\begin{array}{l}\text { Projeto ABEPSS Itinerante }\left(1^{\text {a }}\right. \\
\text { edição) } \\
376 \text { UFAs }(\text { INEP, 2012) }\end{array}$ \\
\hline 2013 & Realização do $4^{\circ}$ ENADE na área & 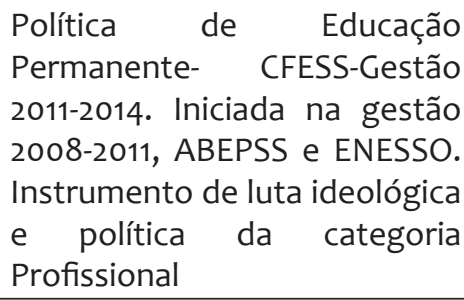 \\
\hline
\end{tabular}




\begin{tabular}{|c|c|c|}
\hline 2014 & $\begin{array}{l}\text { Plano Nacional da Educação } \\
(2014-2024)\end{array}$ & $\begin{array}{l}\text { Projeto ABEPSS Itinerante ( } 2^{a} \\
\text { edição); } \\
\text { CFESS lança o documento } \\
\text { "Meia formação não garante } \\
\text { um direito: o que você precisa } \\
\text { saber sobre a supervisão de } \\
\text { estágio direta em Serviço } \\
\text { Social" 135 mil profissionais } \\
\text { (IAMAMOTO, 2014) }\end{array}$ \\
\hline 2015 & $\begin{array}{l}\text { Plano Nacional da Educação } \\
(2014-2024)\end{array}$ & $\begin{array}{l}\text { Resolução CFESS } 727 / 2015 \text { - } \\
\text { Prorrogação do início do prazo } \\
\text { para recadastramento nacional } \\
\text { dos Assistentes sociais e } \\
\text { realização de pesquisa sobre } \\
\text { o perfil do/a AS na realidade } \\
\text { profissional no Pais }\end{array}$ \\
\hline 2016 & $\begin{array}{l}\text { Impeachment da Presidenta } \\
\text { Dilma Roussef } \\
\text { Início do Governo Michel Temer } \\
\text { (setembro de 2016) } \\
\text { Realização do } 5^{\circ} \text { ENADE na área }\end{array}$ & $\begin{array}{l}\text { Projeto ABEPSS Itinerante }\left(3^{\mathrm{a}}\right. \\
\text { edição) } \\
394 \text { UFAs (Formass/PUCRS, } \\
2016 \text {; e-MEC, 2016) } \\
32 \text { Programas de Pós- } \\
\text { Graduação } \\
170 \text { mil profissionais (CBAS, } \\
2016) .\end{array}$ \\
\hline
\end{tabular}

Fonte: Elaborado pelas autoras (2016).

\section{Reflexões Conclusivas}

As significativas mudanças que ocorreram na política de educação superior brasileira repercutiram na formação em Serviço Social de diversas formas, sendo possível analisá-las à luz de indicadores quantitativos e qualitativos. Assim, nos oitenta anos da profissão, cabe sublinhar que, em menos de uma década (notadamente de 2006 para cá), a categoria acompanhou uma ampla expansão do número de UFAs (394), além do consequente incremento do número de profissionais (170 mil). Devido a essas mudanças, um conjunto de polêmicas foi indicado neste texto e, dialeticamente, as respectivas estratégias de resistência empreendidas pela profissão para garantir o Projeto Profissional. Juntas, elas traduzem o retrato da formação contemporânea em Serviço Social e sinalizam alguns dos seus desafios futuros. 


\section{temporollis}

Na interface da formação com o exercício profissional, destacase o incremento significativo do número de profissionais no mercado de trabalho, gerando a necessidade de monitoramento com relação à inserção no mercado de trabalho desses profissionais, às condições de trabalho e à respectiva remuneração. Sublinha-se a necessidade de empreender estudos que contemplem, também, o trabalho docente na área. Este é um dado que se mantém invisibilizado, o que dificulta a apreensão crítica do processo de formação em uma perspectiva de totalidade.

$\mathrm{Na}$ interface da formação com as mudanças no perfil dos alunos, indica-se a exigência do repensar do ensino, a partir do projeto de formação vigente mediante um conjunto de novas mediações pedagógicas, bem como o repensar da sua inserção nos campos de estágio (em período concomitante às demais disciplinas do curso), nas atividades de extensão e pesquisa (já que uma minoria de UFAs é universidade e, portanto, garante esta indissociabilidade). Além disto, é importante destacar que há uma supremacia do ensino noturno, na oferta do curso, associada ao perfil de aluno trabalhador, que possui baixa renda e, portanto, reduzido poder aquisitivo (o que impacta nas possibilidades de acesso e permanência).

$E$, finalmente, na interface da formação com a garantia qualitativa, alerta-se para a queda da qualidade, se utilizarmos o critério do desempenho da área nos processos avaliativos propostos pelo Estado, bem como nos documentos produzidos pela categoria, os quais denunciam esse comprometimento, o que coloca em xeque as condições objetivas para enraizar o Projeto Profissional no âmbito da formação e, consequentemente, compromete o exercício profissional vinculado à qualificação necessária para incidir com efetividade no objeto profissional (a Questão Social).

Reconhecemos, neste resgate da trajetória histórica dos últimos vinte anos da formação na área, um conjunto dialético de configurações, polêmicas e resistências empreendidas pela profissão, que evidenciam a busca incessante pela garantia do Projeto Profissional, mediante um conjunto de ações as quais se propõem a enraizar as DCs; manter a capacidade político-organizativa da profissão; e, acima de tudo, sintonizar esse Projeto com a direção social da formação. No seu conjunto, ele se traduz num dos mais importantes legados dos últimos vinte anos do Serviço Social no Brasil, portanto, recuperá-lo para apreendê-lo na sua totalidade é fundamental, pois nos permitirá 


\section{tempordis}

avaliar os erros e acertos empreendidos nesse tempo histórico, projetando o futuro que, certamente, já nos impõe uma agenda de renovação das lutas pela formação de qualidade: desafio presente e futuro da profissão e de todos os que se opõem a uma educação mercantilizada e alinhada, exclusivamente, aos interesses do capital.

\section{REFERÊNCIAS}

ABREU, Maria Helena E. A experiência da "ABEPSS ITINERANTE": a atualidade do projeto de formação profissional frente à contrarreforma da educação. Temporalis, Brasília, DF, ano 13, n. 25, p. 113-132, jan./ jun. 2013.

ASSOCIAÇÃO DOS PROFESSORES DA UNIVERSIDADE FEDERAL DE SANTA CATARINA. Cadernos da APUFSC, Florianópolis, n. 2, fev. 2005.

ASSOCIAÇÃO BRASILEIRA DE ENSINO E PESQUISA EM SERVIÇO SOCIAL (ABEPSS). Diretrizes curriculares do curso de serviço social: sobre o processo de implementação. Temporalis, Brasília-DF, Ano VII, n. 14, jul./dez. 2007.

. Plano de trabalho da executiva nacional 2009-2010. 2009. Disponível em: < http://abepssgesto2009-2010.blogspot.com. br/2009/04/conheca-o-plano-de-trabalho-da-abepss.html> Acesso em: 10 jan. 2016.

BOSCHETTI, Ivanete. O desenho das diretrizes curriculares e dificuldades na sua implementação. Temporalis, Brasília-DF, Ano IV. N. 8, p. 17-30, jul./dez. 2004.

. Exame de proficiência: uma estratégia inócua. Serviço Social \& Sociedade, São Paulo, Ano XXIX, n. 94, p. 5-12, 2008.

BRASIL. Lei n. 9.394, de 20 de dezembro de 1996. Estabelece as Diretrizes e Bases da Educação Nacional. Diário Oficial da União, Poder Executivo, Brasília-DF: 23 dez. 1996. Disponível em: < http://www.pla- 


\section{temporalis}

nalto.gov.br/ccivil_03/leis/L9394.htm> Acesso em: 26 jul. 2016.

BRASIL, Lei n. 12.317, de 26 de agosto de 2010. Acrescenta dispositivo à Lei no 8.662, de 7 de junho de 1993, para dispor sobre a duração do trabalho do Assistente Social. Diário Oficial da União, Poder Executivo, Brasília-DF: 27 ago. 2010. Disponível em: <http://www.planalto. gov.br/ccivil_03/_Ato2007-2010/2010/Lei/L12317.htm> Acesso em: 26 jul. 2016.

CONSELHO FEDERAL DE SERVIÇO SOCIAL. Parecer jurídico $n^{\circ}$ 10/07. Oficio Circular CFESS, n. 025/2007, abr. Brasília, DF: 2007.

. Posicionamento das entidades nacionais de serviço social sobre criação e proliferação de cursos de graduação à distância. Brasília, DF: CFESS/ENESSO, abr., 2007. Mimeografado.

. Perguntas frequentes: número de profissionais no Brasil. [2016]. Disponível em: <http://www.cfess.org.br/visualizar/menu/local/perguntas-frequentes. Acesso em: 10 mar. 2016.

. Relatório final do $37^{\circ}$ Encontro Nacional CFESS/CRESS. Brasília, DF 25 a 28 set. 2008. Disponível em: <http://www.cfess.org.br/ arquivos/relatorio_2008.pdf> Acesso em: 20 nov. 2016.

. Carta Aberta aos Estudantes e Trabalhadores dos Cursos de Graduação a Distância em Serviço Social no Brasil. Campo Grande, set. 2009. Disponível em: < http://www.cfess.org.br/arquivos/Carta_ Aberta_EaD_Campo_Grande.pdf> Acesso em: 20 nov. 2016.

. Esclarecimento sobre a implantação da jornada de 30 horas para assistentes sociais sem redução salarial - CFESS. Serviço Social \& Sociedade, São Paulo, n. 105, p. 188-193, jan./mar. 2011.

. Sobre a incompatibilidade entre graduação a distância e Serviço Social. Brasília, DF: CFESS-CRESS, 2014. V. 2. 
CRESWELL, John. W. Projeto de pesquisa: métodos qualitativos, quantitativo e misto. Tradução de Magda Lopes. 3. ed. Porto Alegre: Artmed, 2010.

e-MEC. Instituições de educação superior e cursos cadastrados. [2016]. Disponível em: < http://emec.mec.gov.br/> 20 maio 2016.

FORMASS/PUCRS. Dados obtidos junto ao Grupo de Pesquisa. PUCRS: Porto Alegre, 2016.

GIL, Antonio Carlos. Como elaborar projetos de pesquisa. 5. ed. São Paulo: Atlas, 2010.

MACIEL, Ana Lúcia Suárez. 80 anos do Serviço Social no Brasil: revisitando a sua trajetória histórica e a conformação atual da profissão. In: CONGRESSO BRASILEIRO DE ASSISTENTES SOCIAIS, 15., 2016. Olinda-PE. Anais... Olinda: CFESS, 2016.

; LEWGOY, Alzira Maria Baptista. Apresentação no painel sobre Formação e Trabalho profissional: desafios e tendências. In.: ENCONTRO GAÚCHO DE ASSISTENTES SOCIAIS, 10., 2016. Porto Alegre-RS. Anais... Porto Alegre: CRESS, 2016.

Formação e trabalho profissional: desafios e tendências. In.: ENCONTRO GAÚCHO DE ASSISTENTES SOCIAIS, 10., 2016. Porto Alegre-RS. Anais... Porto Alegre: CRESS, 2016.

MINISTÉRIO DA EDUCAÇÃO. Instituto Nacional de Estudos e Pesquisas Educacionais Anísio Teixeira. Lista funcional de cursos. [2016]. Disponível. em: <www.educacaosuperior.inep.govbr/funcional/lista_cursos.as> Acesso em: 30 dez. 2016.

. Censo da Educação Superior de 2013. 2014. Disponí-

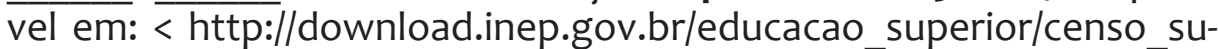
perior/apresentacao/2014/coletiva_censo_superior_2013.pdf> Acesso 


\section{temporollis}

em: 20 nov. 2015 .

- Sistema Nacional de Avaliação da Educação Superior. Relatórios-síntese do Enade em Serviço Social. 2004. Disponível em: < http://download.inep.gov.br/download/superior/enade/Relatorio/Relatorio_area_Servico_Social.pdf> Acesso em: 30 jan. 2016.

Relatórios-síntese do Enade em Serviço Social. 2007. Disponível em: < http://download.inep.gov.br/download/enade/2007/ relatorio_sintese/2007_REL_SINT_SERVICO_SOCIAL.pdf> Acesso em: 30 jan. 2016.

. Relatórios-síntese do Enade em Serviço Social. 2010. Disponível em: < http://download.inep.gov.br/educacao superior/ enade/relatorio_sintese/2010/2010_rel_sint_servico_social.p_pdf> Acesso em: 30 jan. 2016.

Relatórios-síntese do Enade em Serviço Social. 2013. Disponível em: < http://download.inep.gov.br/educacao_superior/ enade/relatorio_sintese/2013/2013_rel_servico_social.pdf> Acesso em: 30 jan. 2016

PEREIRA, Larissa Dahmer. Educação e Serviço Social: do confessionalismo ao empresariamento da formação profissional. São Paulo: Xamã, 2008.

RAMOS, Sâmya Rodrigues. As diretrizes curriculares e a política nacional de estágio: fundamentos, polêmicas e desafios. Temporalis, Brasília, DF, Ano IX, n. 17, p. 21-38, jan./jun. 2009.

RODRIGUES, Mavi. Exame de proficiência e projeto profissional: um debate sobre o futuro do Serviço Social. Serviço Social \& Sociedade, São Paulo, Ano XXIX, n. 94, p. 22-37, 2008.

SILVA, José Fernando Siqueira da; SANT’ANA, Raquel Santos; LOU- 
RENÇO, Edvânia Ângela de Souza. Sociabilidade burguesa e Serviço Social. Rio de Janeiro: Lumen Juris, 2013.

TEIXEIRA Rodrigo; AQUINO Isaura; GURGEL, Telma. Estágio supervisionado em Serviço Social: desfazendo os nós e construindo alternativas. Relatório do Projeto ABEPSS Itinerante 2014. Temporalis, Brasília, DF, Ano XVI, n. 31, p. 401-417, jan./jun. 2016.

TEMPORALIS. Educação em crise e perspectivas de organização política. Brasília-DF, v. 13, n. 25, jan./jun. 2013.

. Formação profissional em serviço social. Brasília-DF, v. 16, n.

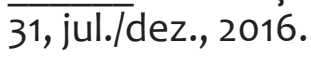

UNIVERSIDADE FEDERAL DO RIO GRANDE DO SUL. Grupo de Estudos e Pesquisa em Formação e Exercício Profissional em Serviço Social GEFESS. Dados obtidos junto ao Grupo de Pesquisa. Porto Alegre, 2016. 


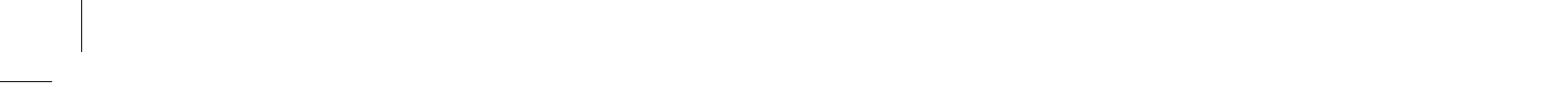

